The Geneva Papers on Risk and Insurance, 21 (No. 80, July 1996), 308-323

\title{
Rights, Solidarity and Cost-effectiveness: Ethical Guidelines for Sustaining Global Health
}

\author{
by Gunnar Bengtsson*
}

\begin{abstract}
In the long run, governments can only achieve what corresponds to deeply rooted values in their populations. I propose to explore the possibilities for sustainable development that may be offered by a set of values suggested for priority setting in health care in Sweden. These comprise human dignity, solidarity, and cost-effectiveness. Of these, human dignity should be broadened to reflect the rights of all living beings in order to be applicable to sustainable development and the use of natural resources. Solidarity and cost-effectiveness are widely applicable with little modifications.
\end{abstract}

Human dignity and solidarity are already broadly supported by large population groups. Cost-effectiveness is often watched with suspicion. It is an important challenge for governments to demonstrate that adherence to cost-effectiveness works in tandem with solidarity to enhance the possibilities to maintain human dignity and sustainable development.

\section{Developing countries}

Human dignity is threatened if human life itself is endangered. The possibilities to sustain life depend to a large extent on the degree of environmental pollution and social conditions. In terms of health effects, an equitable distribution of wealth, and cost-effective pollution abatement are much more important than even preventing war and mitigating large catastrophes. According to the World Bank Development Report 1993, about one-half of the global burden of disease is caused by substances or organisms that occur in too large amounts in our environment. This is completely dominated by microorganisms which are the cause of communicable disease. It has been demonstrated in many national

* Swedish Radiation Protection Institute S-17116 Stockholm Sweden.

Disclaimer: The opinions expressed are those of the author and no official Swedish positions. 
and regional health programs that simple and cheap measures can alleviate these effects. In relation to the effect, the corresponding cost for pollution control in industrialised countries is often a hundred to a thousand times higher. In the extreme case of the nuclear industry, the cost may be exceeded ten thousand times.

Thus, solidarity in allocating resources on a global scale may greatly enhance the possibilities to maintain human life and human dignity.

\section{Industrialised countries}

It is thus possible in developing countries to provide significant improvements in health at low cost. General health programs practised in industrialised countries for many decades have actually eliminated some of the most significant threats to health from environmental pollution. These countries are left with much lower pollution levels and further mitigation is less obvious except for the most ubiquitous contaminants, such as tobacco smoke.

Indeed, most pollutants in industrialised countries imply little threat to health, and prevention of pollution is often likely to be much more costly than other means of improving health. Actually, solidarity seems to be crucial here, in the sense that a more equitable distribution of wealth in industrialised countries is correlated with a higher mean life expectancy.

\section{Sweden}

Some examples from recent Swedish work on economic instruments in environmental policy, and planning for possible cathastrophes will illustrate the general proposals on the ethical foundation for environmental policy.

\section{An ethical basis for sustainable development}

In the long run, governments can only achieve what corresponds to deeply rooted values in their populations. I propose to explore the possibilities for sustainable development that may be offered by a set of values suggested for priority setting in health care in Sweden (Government investigation on priority setting, 1995). These comprise human dignity, solidarity, and cost-effectiveness.

\subsection{Human dignity and protective value}

Of these, human dignity could be broadened to reflect the rights of all living beings in order to be applicable to sustainable development and the use of natural resources. The concept of human dignity is interpreted as requiring certain human rights, equal for all human beings. These are very fundamental, such as the rights to live, to be free, to have personal security and be respected. All human beings should have the same access to these rights, nobody being superior to anybody else in these respects.

Human dignity is tied to one's existence as a human being, not to one's function in particular respects. We are all different with respect to those functions, but acknowledging those differences is not an infringement of our human dignity. 
This concept of human dignity could be transferred to a concept of ecological dignity. Ecosystems besides man could be assigned their dignity in their own right, irrespective of their significance for man. Such an ethic has its advocates, for instance in terms such as "deep ecology" (Naess 1989), but a more anthrocentric perspective is widely acclaimed (IUCN 1980). My personal preference is to assign man human dignity, and other living beings a protective value which diminishes in relation to their deviation from mature man in organisation and cognitive capacity. This has been a way in Swedish medical ethics to partly reconcile widely differing views on the dignity of the embryo and fetus. The protective value of an embryo thus increases as the pregnancy proceeds, and it has a recognised human dignity when it is fully developed many weeks before birth. Similarly, species being near man, such as dwarf schimpanzees, have a considerable protective value whereas individual intestinal bacteria or algae have very little. By analogy, ecosystems of obvious significance for man have a high protective value whereas systems of low productivity such as limited parts of the polar ice cap ecosystem have little protective value.

\subsection{Solidarity}

Solidarity implies that one decides to devote resources to those individuals who have the largest needs for them to improve health and quality of life. The principle has been discussed e.g. by Rawls (1971). The principle of solidarity may lead to improved health within a given frame of resources, even in wealthy societies. This is suggested by the finding from industrialised societies that the mean life expectancy is higher in societies where a large share of the resources go to the poorest segments, as shown in Figure 1. For poorer societies, it is obvious that the mean life expectancy of around 40 years in poorer countries is strongly correlated to poverty. Solidarity is supported by all political parties in Swedish health care policy and inscribed in Swedish health legislation.

As the case is with many ethical principles, solidarity cannot be applied in isolation this might lead to unreasonable consequences. One very difficult situation appears when one individual or practice requires extremely large resources, thus detracting resources from other urgent applications. However unpleasant the choice, it must be made and the solidarity weighted against the joint common utility.

\subsection{Cost-effectiveness}

Many people have an instinctive aversion to discussing costs in relation to measures for protection of health and the enviroment. One-sixth of all health care politicians in a region in Sweden claimed that economic considerations must never enter the responsible doctors choices among treatment alternatives (Björk and Rosén 1993). One-half of all respondents in Sweden said that no sum is high enough for the state or municipality to spend to prevent the loss of a life (Sjöberg 1991). These positions are obviously unrealistic - it would mean that one might spend all available resources to save only one person. Deeper ethical considerations (e.g. Williams 1992) often lead to an appreciation of the possibilities of doing good by using resources in a cost effective way. The Swedish priority setting investigation (Government investigation on priority setting, 1995) advocates cost effectiveness as one of the most important ethical foundations for priorities in health care, but gives it the limited interpretation of choosing, for the same disease, among different alternatives, having different effectiveness and costs. For discussions on measures related 
Figure 1. Relation between mean life expectancy and degree of equality in income distribution for OECD countries 1981. Each point represents one country. BRD stands for what was then West Germany. The income distribution index represents the average of the available income after taxes and associated transfers, for the 70 per cent of the population having the lowest income in relation to the average. Based on Wilkinson 1992.

\section{Mean life expectancy / years}

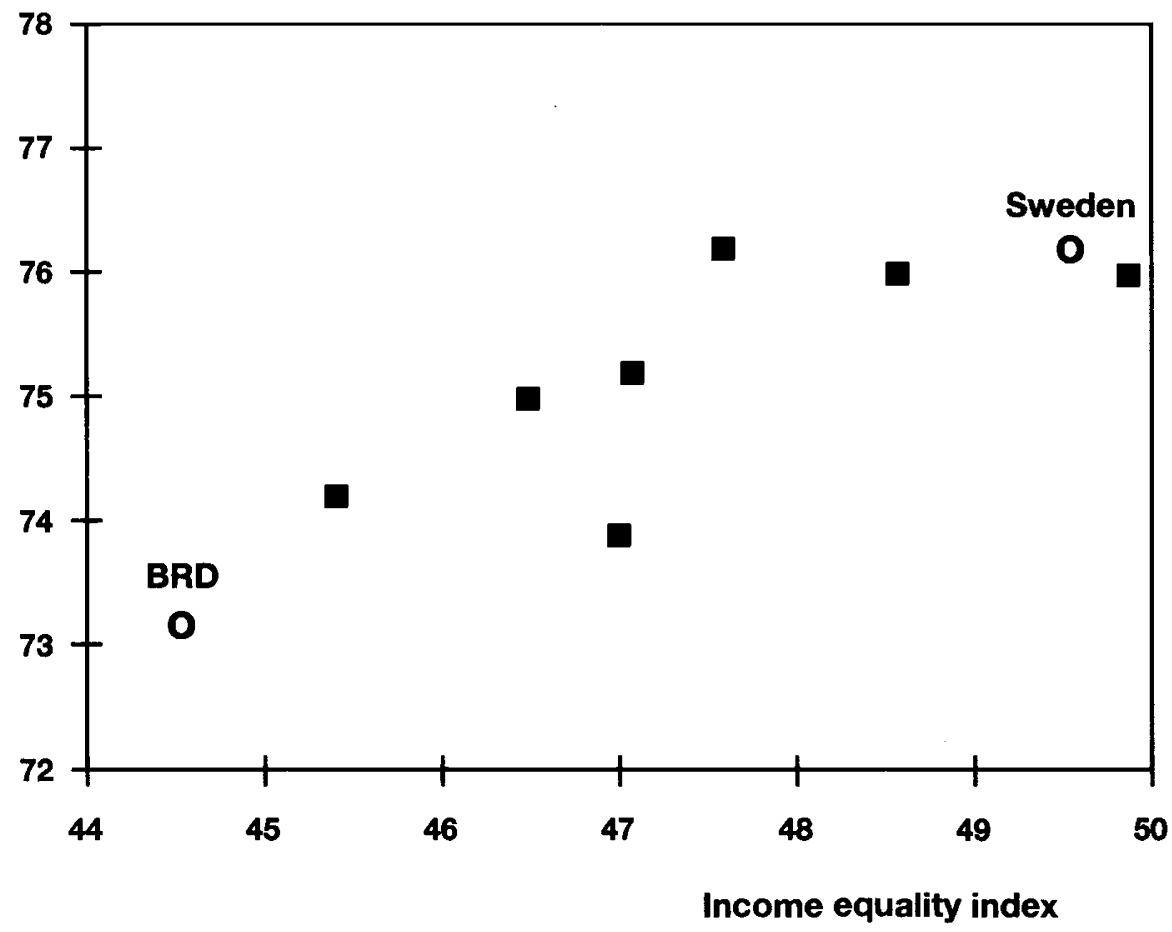

to sustainablity, a broader application is necessary, although very difficult since many value judgments enter the assessments. In general, it is an important challenge for governments to put the spotlight on the ethical significance of cost-effectiveness and promote a debate on its role for sustainable development.

\subsection{In line with $E U$ principles}

The proposed ethical basis has a strong support in policy documents on sustainable development. For instance, among the 12 principles for sustainable development proposed for the European Union (General Consultative Forum on the Environment, 1995), the fifth is a solidarity principle: The burdens and benefits of policies should be shared equitably by all segments of society. The sixth is a cost-benefit principle: Policies should have 
clear objectives and be based on detailed assessments of the issues and related risks, assessment of the impact, sound science and sensible balance between costs and benefits leading to full internalisation of all costs. The seventh is a principle of balance: Economic and social development, environmental protection and social equity are interdependent and all policies should be tested for their impact on each area and not considered in isolation.

\section{A perspective on global health}

Human dignity is coupled with existence - if you do not exist you do not have human dignity. It is obvious that if you live on the margin of existence you will generally find it difficult to maintain dignity - for most people, the urge to survive is stronger than their quest to maintain dignity. In order to explore the application of the ethical values suggested, it is thus interesting to examine how the possibilities of survival on a global scale are related to solidarity and cost effectiveness.

\subsection{The global burden of disease and its geographical distribution}

The World Bank and the World Health Organisation have made an extensive review of the health status of peoples from our whole planet (World Bank 1993). One of the shocking results is the unbelievable inequality in the geographical distribution of health. This is brought out very clearly by the median age at death in different countries or regions. For large regions in Africa, it is as extraordinarily low as around 5 years, as compared with above 75 years for industrialised countries.

\subsection{Global health and environmental pollution}

What are the reasons for these very large differences? Figure 2 hints to a quite clear answer. The burden of disease is measured in terms of loss of disability adjusted life years, DALY, (World Bank 1993). A year of life lost is discounted at 3 per cent per year, so that for instance for a female, the maximum number of adjusted years of life lost is 37, which occurs at 10 years of age; death at 50 years of age incurs an adjusted loss of 17 years and death at 70 a loss of 7 years. The losses due to sickness without death are also disability adjusted, so that a year of pelvic inflammatory disease gives a disability adjusted loss of 0.22 years, and a year of blindness a loss of 0.6 years. The concept also includes an age weight where the relative value of a year of life is 0 at birth, has a maximum of 1.4 at 25 years of age and decreases to 0.4 at age 90 .

For the whole world, communicable diseases are a major cause of loss of health. These have been controlled to a large extent in the affluent world. Consequently, noncommunicable disease appears as a major cause instead.

In a broad definition, the microorganisms responsible for the spread of communicable diseases constitute environmental pollutants. Figure 2 indicates that over most of the world, control of these pollutants should be of major concern. As Figure 3 shows, many means of control are known and the costs of using them are quite low. There is simply not room for much loss of health due to other pollutants. 
Figure 2. Main causes of loss of health in the world in general and in its affluent parts, defined as the established market economies (almost identical to the OECD countries) The figure gives the losses of disability adjusted life years (see text) categorised in three major groups. The area of the circle sectors is proportional to the individual risks of loss of health.
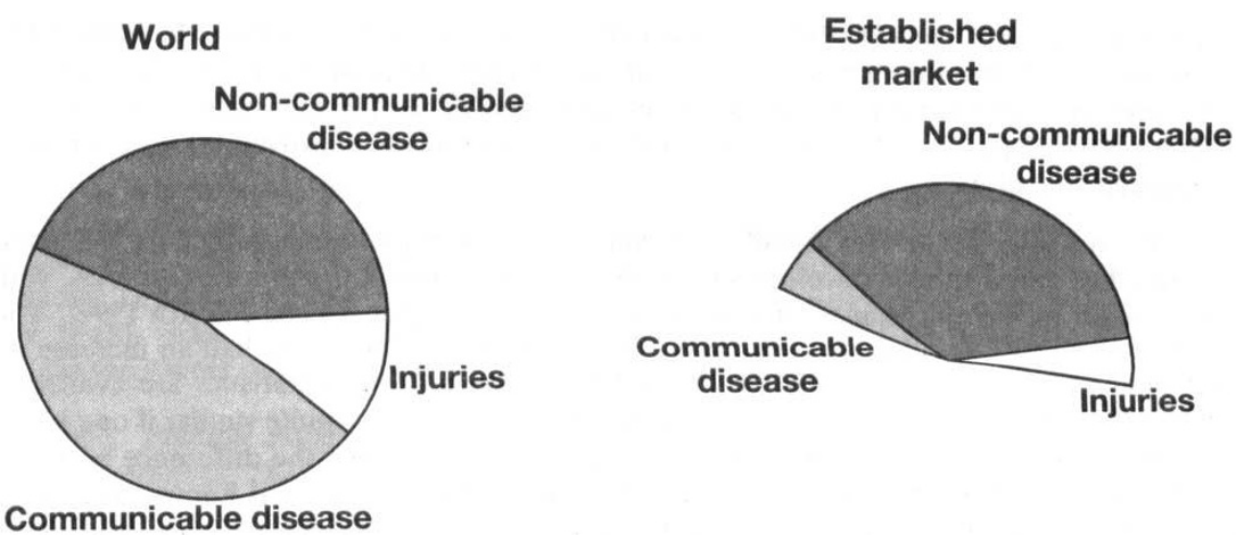

Figure 3. Reduction in health losses due to communicable diseases which is achievable by some identified simple countermeasures at low cost. Three actions are considered: an expanded program on immunisation, and supplementation to children of food and of vitamin $A$. The average cost of the reduction is less than 20 USD per disability adjusted life year saved.

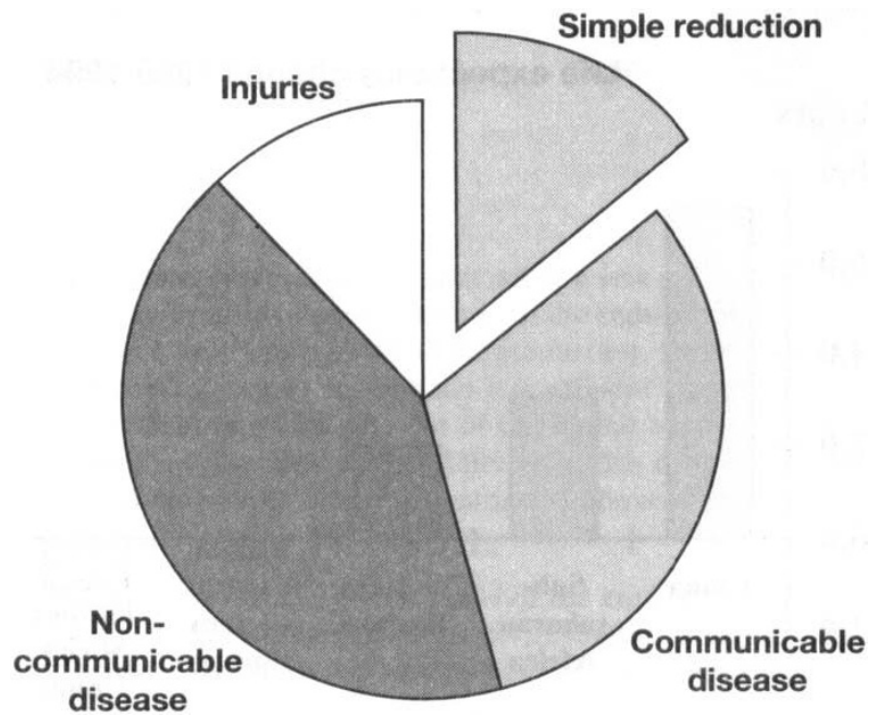


In contrast, the microorganisms have already been controlled in the affluent world. Here it is much more interesting to review the possible influence on health of the reduction of other environmental exposures.

Over the last decades, there has been a worldwide increase in life expectancy (World Bank 1993). China has had the highest rise in life expectancy, with an increase of about 7 years per decade. The established market economies, which already have the highest life expectancy, still have an increase of 2-3 years per decade. At least this is an indication that whatever environmental pollution might mean in terms of ill health, this is significantly offset by other positive developments, such as the continued improvement in control of communicable disease.

If one goes more into detail, however, a gloomier picture may appear. Western Europe has had a similar development as that of the established market economies, with an increase in life expectancy of a bit more than 2 years per decade (WHO 1994). The countries of central and eastern Europe (CCEE), however, have only had an increase by less than half a year per decade. In the last few years for which statistics are available, there has even been a decrease in life expectancy. The situation is quite similar if one looks instead at the life expectancy at 45 years of age, so on the whole, the difference between the two parts of Europe it is not a matter of child mortality. Since it is known that there has been considerable environmental pollution in these countries, there is room for doubt that such pollution may lead to a significant loss of health, and that this may have caused a loss up to several years in the mean life expectancy. The development is summarised in Figure 4.

Figure 4. Trends in mean life expectancy at birth for several regions around 1990. The trend gives the expected increase in mean life expectancy in years for the period 1985-1994, extrapolated from data available for 1985-1990. (Based on World Bank 1993 and WHO 1994).

\section{Life expectancy change 1985-1994}

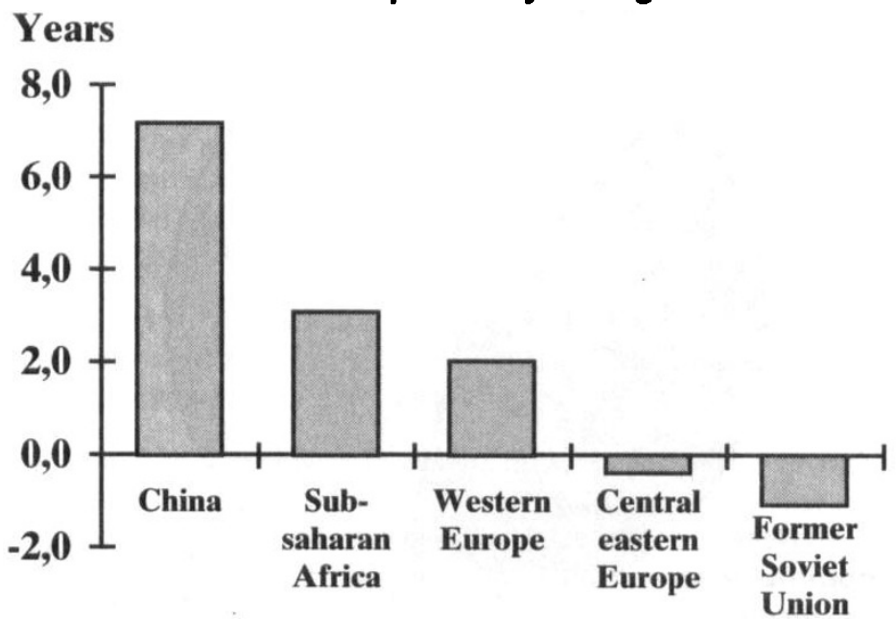


I will soon go into the scanty estimates which are available on health effects of other pollutants than microorganisms. First, however, I would like to stress the importance of interactions between microorganisms and other pollutants. For instance, acute respiratory infections are to a large extent depending on indoor air pollution. It has been estimated that acute infections, principally pneumonia in children, cause a loss of about 120 million DALY per year, as compared to the total loss of almost 1400 million DALY per year from the global burden of disease, or almost $10 \%$. Reducing indoor air pollution from very high to low levels could potentially halve the incidence of childhood pneumonia (World Bank 1993). The interplay between several factors in causing disease can thus be very significant.

For this reason, I choose to refer to estimates of disease burdens that can be averted by actions against environmental pollutants, rather than burdens caused by the pollutants. Figure 5 shows to what extent some feasible interventions may reduce the global burden of disease. The interventions concern mitigation of out-door and indoor air pollution, where the health risks are dominated by respiratory disease, and of occupational exposures, where the cancer dominates among the health consequences.

Figure 5. Possible aversion of disease through some feasible interventions against environmental pollution. The expanded part of the diagram shows the relative importance of some important interventions. Derived from World Bank 1993.
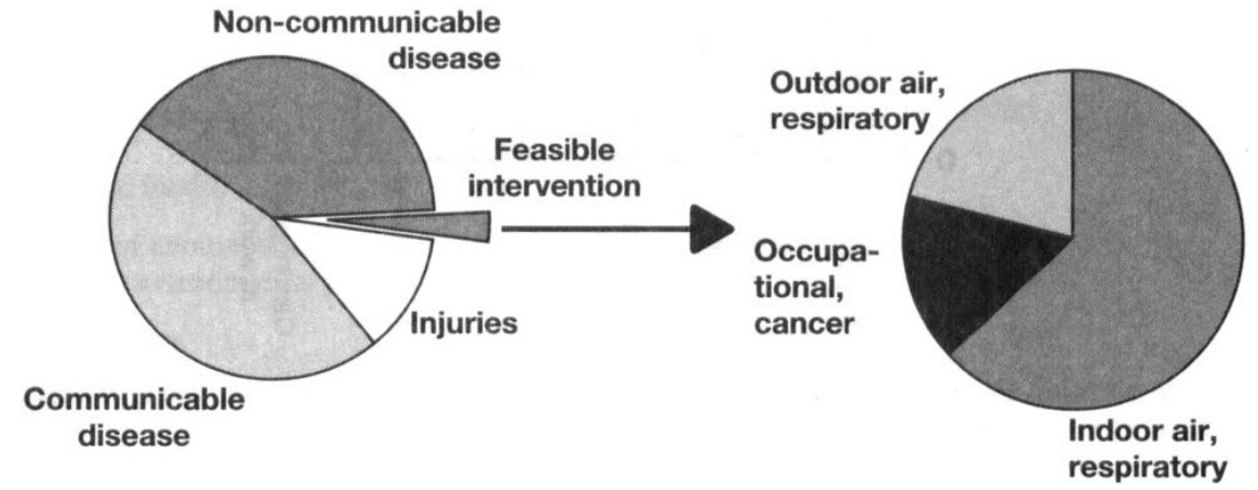

The total intervention corresponds to alleviating a few per cent of the global burden of disease. This is relatively little in comparison with the reductions possible with reference to communicable disease (cf. Figure 3). To illustrate further, I would like to quote possible tobacco and alcohol control programs. For the less affluent parts of the world, such programs could avert less than one-half per cent of the global burden of disease, at a cost of about 50 USD per averted disability adjusted life year; this is more than twice the cost of the actions against communicable diseases mentioned above, per year of healthy life gained.

An extensive review has recently been made of the environmental health problems in an affluent part of the world, Europe (WHO 1994). Numerical estimates of health consequences of environmental pollution are scarce, whereas the magnitude of the populations exposed is easier to assess, as illustrated in Figure 6. 
Figure 6. Exposures of the European population to selected environmental pollutants. The percentages apply to the European population of 852 million persons. (Based on WHO 1994 Tables 1 and 2).

The criteria for calculation of the numbers are:

- Exceeding the $24 \mathrm{~h}$ WHO air quality guideline for sulphur dioxide at least one day per year

- Being married to a smoker or, for infants, having a mother smoking at home

- Occurrence of allergens and carcinogens at work

- Occurrence of other chemicals at work above occupational limits

- More than 200 becquerel of radon gas per cubic meter of air at home

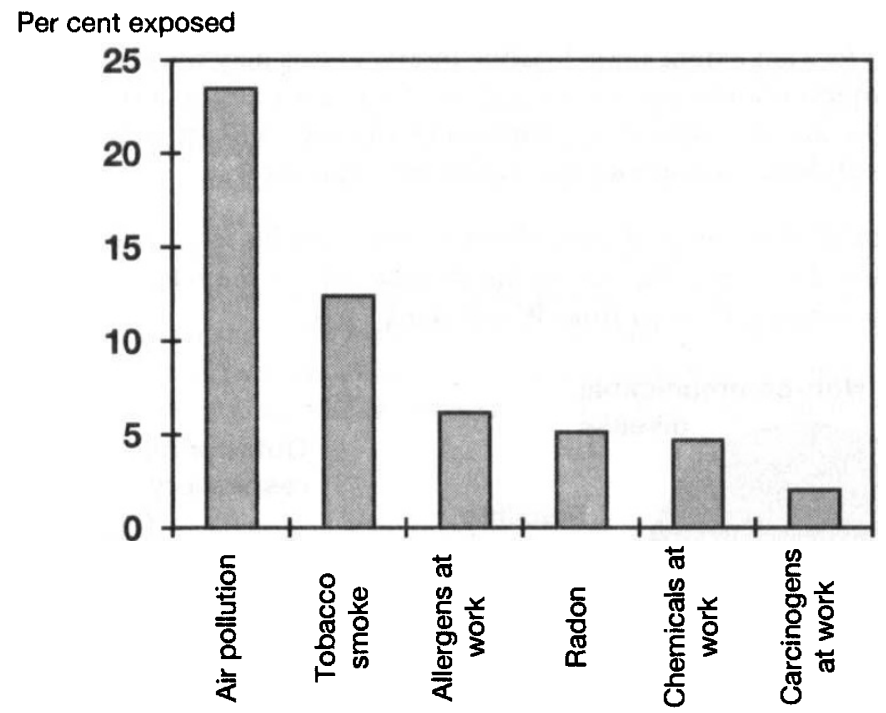

In addition to the exposures in Figure 6, a large fraction of the population is exposed to solar ultraviolet radiation that may cause skin cancer.

The impact of environmental conditions in terms of sickness of the population in Europe is hard to estimate at present. Despite the rather extensive exposures, however, the health risks are judged to be moderate. For instance, carcinogens in water are not considered to be a health risk, in food probably associated with small risks, in waste not coupled with any convincing evidence of cancer risks and in occupational exposure situations relatively effectively controlled. The most common outcomes of environmental exposures are mild illnesses, which are difficult to register by existing systems. Fatal outcomes rarely result from environmental exposures and if so constitute a small fraction of all deaths.

Special concern is warranted, however, for the countries of central and eastern Europe, and particularly for the newly independent states of the former Soviet Union (compare figure 4). Another word of warning pertains to birth defects, for which the cause of a large proportion is unknown; environmental exposure may play an important role. 
The overall picture that emerges is thus that exposures to environmental pollutants other than microorganisms are quite common, but the health effects are moderate in countries that have managed to get a reasonable control over the pollution indoors and outdoors. There are, however, examples of probably strong health effects when the pollution is extensive, such as indoors in developing countries and in the general environment in many states associated with the former Soviet Union. Synergism with other factors such as respiratory infections may be very important. All estimates are quite rough and affected by many sources of uncertainty (Bengtsson 1995).

\subsection{Wars, disasters and general health}

How do the threats to health from poverty and environmental pollution compare with the threats from various types of disasters such as natural catastrophes, wars and industrial catastrophes? Although only poor statistics are available, the general pattern is evident enough, as appears from Table 1 .

Table 1. Influences on health and survival of various conditions. The data are very approximate and derived from the World Bank (1993), the Threat and risk investigation (1995) and the Commission on Global Governace (1995).

\section{Condition}

Cause: Poor living conditions, disease

- Thereof avoidable by better child and maternal health, at $<500$ USD/death

- Thereof avoidable by intervention against environmental pollution

Cause: Wars

Cause: Natural catastrophes

Cause: Industrial disasters

\section{Premature deaths annually}

Tens of millions

Millions

Fractions of millions

Hundreds of thousands

Hundreds of thousands

Thousands

\section{Relative order of magnitude}

1

0.1

0.01

0.01

0.01

0.0001

Poverty, lack of education, lack of good housing and other living conditions: these are the important factors responsible for loss of health today, mainly in developing countries. Wars and natural catastrophes, however grim, are much less important, and at the same level as health effects caused by avoidable environmental pollution, and industrial disasters lag far behind in global importance.

\subsection{Radiation in comparison with other agents}

Effects of radiation on human health have recently been reviewed by UNSCEAR (1993). They are dominated by the induction of cancer which may occur with a latency of years to decades after exposure.

Figure 7 gives the contributions of ionising radiation exposure to the global burden of disease, based on the most recent estimates of radiation exposures and risks, and a provi- 
sional assessment of the loss of disability adjusted life years per unit collective dose. Radiation accounts for only less than 1 per cent of the global burden of disease. Much less than one-hundredth of one per cent is due to nuclear power in combination with all exposures except those from natural radiation, irradiation of patients in medicine, and nuclear weapons tests.

The costs of mitigation of radiation exposures are often high in comparison with the costs discussed for other countermesures in this report. For instance, the Swedish Radiation Protection Institute considers it reasonable to spend up to 400000 USD to avert one mansievert, or $0.7 * 400000=280000$ USD/DALY, and Sweden's nuclear industry uses a value corresponding to about 1 million USD/DALY (Bengtsson and Moberg 1993). Both of these are more than 10000 times higher than the corresponding cost of simple countermeasures against communicable diseases, 20 USD/DALY.

Figure 7. Fraction of global burden of disease attributable to carcinogenic effects of ionising radiation, and its breakdown into different components. The category All others includes industrial uses of radiation including nuclear power.

Based on the 50-year collective dose of 848 Mansievert given in UNSCEAR 1993. A rounded figure of 0.7 disability adjusted life years lost per mansievert of collective effective dose has been assumed ( 0.07 adjusted cases of cancer per mansievert times 10 adjusted years lost per cancer).
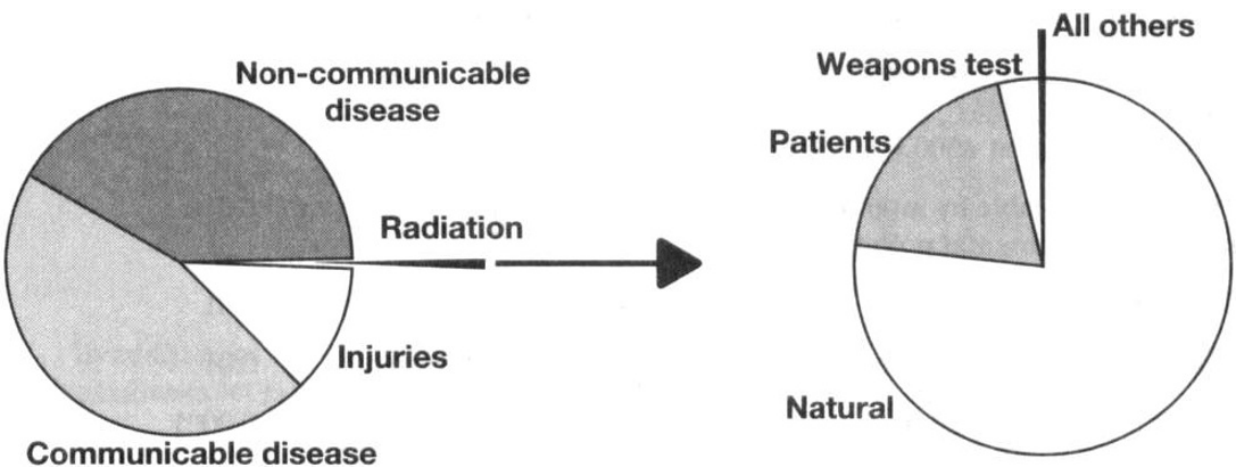

\section{Some small steps towards sustainability}

In my view, the overriding goal for sustainable development is to improve living conditions in developing countries so as to minimise the health losses due to contageous disease. Ending wars, alleviating natural catastrophes and reducing environmental pollution are other Herculean challenges facing governments and other parts of the global community. My ethic is an anthropocentric one. Solidarity and cost-effectiveness should be leading the work towards human sustainability. It is hard enough to achieve these goals while caring for the ecosystems to the extent that this helps maintain productivity for the purposes of sustaining man. I have thus little sympathy for affording the ecosystems a dignity of their own, worthy of significant efforts even when this would be contrary to human sustainability. 
Every individual and even every government can only take small steps towards a more sustainable world. A first prerequisite for concerted and efficient action is a set of common values as just discussed. Planning and implementation starting from these values require large efforts. I will share with you one example of planning and one of implementation, hoping that these might generate some ideas on actions in other fields or other geographical areas.

\subsection{Planning for major threats in an industrialised society}

Prevention is better than cure. But modern societies are exposed to many threats, all of which cannot be prevented. A recent Swedish investigation has listed seven threats to modern Sweden that are within the realms of possibility and for which there should be a preparedness (Threat and risk investigation 1995):

- massive immigration to Sweden of refugees from Baltic countries

- long-term loss of electricity supply

- extensive loss of water supply

- radioactive fallout in an agricultural area

- inundations in an area consisting of several administrative regions

- severe lack of supply of high technology goods

- large gas release in a city center.

In very broad terms, Table 2 represents the preventive measures already taken and the proposed further actions which could alleviate a scenario, should it be realised.

Table 2. Prevention and mitigation in cases of major crises in Sweden according to proposals by a Swedish government committee (Threat and risk investigation 1995).

\begin{tabular}{|c|c|c|}
\hline Scenario & Examples of preventive actions taken & Proposed further prevention \\
\hline $\begin{array}{l}\text { Immigration } \\
\text { health }\end{array}$ & $\begin{array}{l}\text { Normal capacity to accept refugees is } \\
\text { about } 1 \% \text { of the population }\end{array}$ & $\begin{array}{l}\text { Improved preparedness for } \\
\text { care and epidemic mitigation }\end{array}$ \\
\hline Electricity loss & $\begin{array}{l}\text { Rerouting of supply lines } \\
\text { Redundant capacity in production } \\
\text { High repair capacity } \\
\text { Robust designs withstanding ice, salt }\end{array}$ & $\begin{array}{l}\text { Stimulate local spare power } \\
\text { sources, e.g. for animal } \\
\text { breeding enterprises }\end{array}$ \\
\hline Water loss & $\begin{array}{l}\text { Robust designs } \\
\text { Most municipalities have spare } \\
\text { supplies and double supply routes }\end{array}$ & $\begin{array}{l}\text { Survey and improve spare } \\
\text { supplies and distribution lines } \\
\text { Mandate to prescribe rationing }\end{array}$ \\
\hline $\begin{array}{l}\text { Radioactive } \\
\text { fallout }\end{array}$ & $\begin{array}{l}\text { Robust designs } \\
\text { International information and } \\
\text { assistance systems } \\
\text { Aid to eastern nuclear plants } \\
\text { Emergency preparedness }\end{array}$ & $\begin{array}{l}\text { Further capability for } \\
\text { measurement and reporting } \\
\text { National expert group for } \\
\text { decontamination } \\
\text { Preparedness to compensate } \\
\text { affected enterprises }\end{array}$ \\
\hline
\end{tabular}


Inundations (This scenario is still under consideration)

Technology Nationally coordinated storage

supply

Gas release
Storage for specific systems, e.g. for payment or telecommunications

Exercises, drills, local coordination
Stimulation for supplementary imports Preparedness for rationing

Extended scope of major exercises

In addition to detailed proposals for the specific scenarios, four areas of action are of general importance for most of the scenarios:

- Stronger central control and possibilities of legally binding coersion

- Prevention in planning of hazardous activities, e.g. in their siting, construction, equipment and organisation

- Improved electricity supply

- Integration of actions into a joint scale of planning from crises to catastrophes to war.

\subsection{Implementing environmental policy using economic instruments}

In the principles for sustainable development proposed for the European Union (General Consultative Forum on the Environment, 1995), the tenth principle states that, in addition to appropriate regulatory measures, a mix of market-based instruments, including fiscal and economic incentives and a flexible approach, should be used to harness private energies and capital to promote a sustainable development. For the last two decades, Sweden has gradually increased the use of economic instruments until the breakthrough around 1990 (Ministry of the Environment and Natural Resources 1994). The use of the instruments has had direct effects, such as reducing supply and/or demand, and indirect effects such as promoting recycling or environmental protection measures. These are summarised in Table 3.

In general, the uses of economic instruments have achieved their goals, at least partly, and at strikingly low administrative costs. Sweden has never had any problems with the trading rules organisation GATT concerning the economic instruments and is not expecting any. Some constraints are expected with the new membership in the European Union, for instance with reference to emissions from cars. In general, however, environmental taxes combined with reduced taxes on labour are in line with the ecological tax shift discussed in EU's white book on economic growth, employment and competitiveness, and with the principles for sustainability mentioned above.

\section{Discussion and conclusions}

Globally, health effects of environmental pollutants are completely dominated by microorganisms which are the cause of communicable disease. It has been demonstrated in many national and regional health programs that simple measures can alleviate these effects at quite low costs and without any detailed knowledge about the health impact of the pollutants. General health programs in industrialised countries for many decades have in this way resulted in the elimination of some of the most significant threats to health 
from environmental pollution. These countries are left with much lower pollution levels and further mitigation is less obvious except for the most ubiquitous contaminants, such as tobacco smoke. The gains in health and wellbeing from the mentioned type of programs are large even in comparison with what is to be gained from actions against wars and disasters. Modern society, however, is so vulnerable that anticipating disasters is an activity that cannot be neglected. The quoted Swedish example in this field shows that imaginative planning could alleviate stresses from industrial disasters or large population movements.

Table 3. Effects and administrative costs of economic instruments for environmental protection. The estimates are very approximate. For details, see Ministry of the Environment and Natural Resources, 1994

\begin{tabular}{|c|c|c|c|c|}
\hline $\begin{array}{l}\text { Environmental } \\
\text { charge/tax }\end{array}$ & $\begin{array}{l}\% \text { of con- } \\
\text { sumer } \\
\text { price }\end{array}$ & Direct effects & $\begin{array}{r}\text { Indirect effects Ad } \\
\text { tt }\end{array}$ & $\begin{array}{l}\text { dm. costs } \\
\% \text { of } \\
\text { turnover }\end{array}$ \\
\hline $\begin{array}{l}\text { Scrapped cars } \\
\text { charge }\end{array}$ & $0.5-1$ & - & $\begin{array}{l}\text { Collection rate } \\
\text { about } 99 \%\end{array}$ & $<2$ \\
\hline $\begin{array}{l}\text { Fertilizer nitrogen } \\
\text { and phosphorus } \\
\text { charges }\end{array}$ & $10-30$ & $\begin{array}{l}\text { Use } \sim \text { halved } \\
1980 \rightarrow 1992\end{array}$ & $\begin{array}{l}\text { Financing of } \\
\text { councelling }\end{array}$ & $<0.4$ \\
\hline Petrol lead tax & $2-8$ & $\begin{array}{l}\text { Unleaded use } \\
\text { dramatically increased. } \\
\text { New qualities developed }\end{array}$ & & $<0.01$ \\
\hline $\begin{array}{l}\text { Domestic air } \\
\text { travel hydrocarbon } \\
\text { and nitrogen } \\
\text { oxide taxes }\end{array}$ & 20 & $\begin{array}{l}\text { Some investment made } \\
\text { earlier }\end{array}$ & $\begin{array}{l}\text { Augmented } \\
\text { consciousness about } \\
\text { exhaust control }\end{array}$ & ut \\
\hline $\begin{array}{l}\text { Lead battery } \\
\text { charges }\end{array}$ & $6-8$ & None & $\begin{array}{l}\text { Collection rate } \\
\sim 100 \%\end{array}$ & 1 \\
\hline $\begin{array}{l}\text { Small battery } \\
\text { charge } \\
(\mathrm{Hg}, \mathrm{NiCd})\end{array}$ & & New batteries developed & $\begin{array}{l}\text { Collection rate } \\
30-90 \%\end{array}$ & $<0.1$ \\
\hline $\begin{array}{l}\text { Carbon dioxide } \\
\text { tax (differen- } \\
\text { tiated, industry } \\
\text { paying } 25 \% \text { of } \\
\text { household tax) }\end{array}$ & $10-30$ & $\begin{array}{l}\text { Biofuel share increased } \\
7 \% \rightarrow 30 \% \text { in district } \\
\text { heating } 1980 \rightarrow 1992 \text { but } \\
\text { decreased in pulp and } \\
\text { paper industry }\end{array}$ & $\begin{array}{l}\text { Some effect on } \\
\text { investment plans } \\
\text { for converting } \\
\text { plants }\end{array}$ & $<0.1$ \\
\hline $\begin{array}{l}\text { Sulphur tax on oil, } \\
\text { peat and petrol }\end{array}$ & $<10$ & $\begin{array}{l}\text { Sulphur emissions from } \\
\text { oil combustion } \sim \text { halved } \\
1990 \rightarrow 1992\end{array}$ & - & $<1$ \\
\hline
\end{tabular}


Nitrogen oxide charge for large combustion plants

Environmental $<20$ classification of diesel fuels

$$
\begin{array}{cl}
<10 \quad \begin{array}{l}
\text { Nitrogen oxide emissions } \\
\text { reduced } 40 \% \\
1990 \rightarrow 1992
\end{array}
\end{array}
$$

$<1$

$3 / 4$ of all fuels now in

$<1$ two lowest classes instead of highest, $1991 \rightarrow 1993$

Programs for limiting the health impacts of environmental pollution in industrialised countries, apart from some obvious candidates such as tobacco smoke, have in no way the same urgency as a reduction of the health effects from microorganisms in developing countries. Indeed, most pollutants show little threats to health, and prevention of pollution is often likely to be much more costly than other means of improving health. Considerable attention to cost-effectiveness is an ethical imperative. The quoted Swedish example shows that taxes and charges can be used as instruments to achieve environmentally sound actions at low administrative costs. 


\section{REFERENCES}

BENGTSSON G. and MOBERG L.: What is a reasonable cost for protection against radiation and other risks? Health Physics 64, 661-666, 1993.

BENGTSSON G: Uncertainties in the health impact from environmental pollutants. Paper at International Conference on Radiation and Society: Comprehending radiation risk, Paris 24-28 October, 1994. Published by International Atomic Energy Agency, Vienna 1995.

BJÖRK S and ROSÉN P: Priorities in health care. IHE Working document 1993:1. (In Swedish). IHE, S-22223 Lund, Sweden, 1993.

Commission on Global Governance: Our Global Neighbourhood. Oxford University Press, Oxford 1995.

General Consultative Forum on the Environment: Principles for sustainable development, as referenced in CORDIS focus No. 35, 31 March $1995 \mathrm{p} 1$.

Government investigation on priority setting: The difficult choices in health care. (In Swedish). SOU 1995:5. Fritzes, Stockholm 1995.

IUCN: The World Conservation Strategy: Living resource conservation for sustainable development. International Union for the Conservation of Nature and Natural Resources, Gland, Switzerland 1980. (A draft chapter on ethics for the revised edition was presented to the 17 th General Assembly of IUCN in 1988).

Ministry of the Environment and Natural Resources: The Swedish Experience - taxes and charges in environmental policy. The printing works of the cabinet office and ministries, Stockholm 1994.

NAESS A: Ecology, community and life style. Cambridge University Press, Cambridge 1989.

RAWLS J: A theory of justice. Harvard University Press 1971.

SJÖBERG L: Psychological reactions to a nuclear accident. Lecture at Nordic Radiation Protection Society meeting, Tromsö 1991. Center for risk research, Stockholm School of Economics, Stockholm 1991.

Threat and risk investigation: A safer society. (In Swedish). SOU 1995:19. Fritzes, Stockholm 1995.

UNSCEAR: Sources and effects of ionizing radiation. United Nations Scientific Committee on the Effects of Atomic Radiation, 1993 Report to the General Assembly, with annexes. United Nations sales publication E.88.IX.7. United Nations, New York 1993.

World Bank: Investing in health. World development report 1993. Oxford University Press, New York 1993.

WHO: Concern for Europe's tomorrow. Health and Environment in the WHO European region. Summary. WHO Regional Publications, European Series, No. 53. World Health Organisation, Regional Office for Europe, Copenhagen 1994.

WILKINSON R G: Income distribution and life expectancy. British Medical Journal 1992, 304:429446.

WILLIAMS A: Cost-effectiveness analysis - is it ethical? Journal of Medical Ethics 18: 7-11, 1992. 